\title{
Indutores de resistência abióticos no controle da fusariose do abacaxi
}

\author{
Luiz Gustavo de Lima Melo(1), Erlen Keila Candido e Silva(2), José Ribamar Muniz Campos Neto(2), \\ Severina Rodrigues de Oliveira Lins ${ }^{(1)}$, Antônia Alice Costa Rodrigues ${ }^{(2)}$ e Sônia Maria Alves de Oliveira(1)
}

\begin{abstract}
(1)Universidade Federal Rural de Pernambuco, Avenida Dom Manuel de Medeiros, s/no, Dois Irmãos, CEP 52171-900 Recife, PE, Brasil. E-mail: luizgustavo_88@hotmail.com, linsnina@hotmail.com, oliveirasonia55@yahoo.com.br (2)Universidade Estadual do Maranhão, Laboratório de Fitopatologia, Caixa Postal 09, CEP 65054-970 São Luís, MA, Brasil. E-mail: erlenkeila@yahoo.com.br, munizneto@msn.com, aacrodrigues@outlook.com
\end{abstract}

Resumo - O objetivo deste trabalho foi avaliar o efeito de indutores de resistência abióticos no controle da fusariose (Fusarium guttiforme) do abacaxizeiro na fase pré-colheita, em área de ocorrência natural da doença, e verificar se promoveram alterações físico-químicas e bioquímicas nos frutos. Os produtos testados foram fosfito de potássio, fosfito de cálcio, fosfito de cobre, Agro-Mos, silicato de cálcio, Biopirol e Bion pulverizados em campo, nas dosagens recomendadas pelos fabricantes. Fosfito de potássio, Biopirol e fosfito de cobre foram os mais eficientes na redução da incidência da fusariose do abacaxizeiro em campo, com 91,67, 70,01 e 67,68\% de controle, respectivamente. As análises físico-químicas mostraram que os tratamentos não promoveram alteração no $\mathrm{pH}$, nos sólidos solúveis totais e na acidez total dos frutos, enquanto, nas análises bioquímicas, apenas a $\beta$-1,3-glucanase apresentou menor atividade em relação à testemunha (água destilada esterilizada), com exceção do tratamento com fosfito de potássio. Assim, a adubação foliar com fosfito de potássio e fosfito de cobre, assim como o tratamento com o Biopirol, podem auxiliar no controle da fusariose do abacaxi.

Termos para indexação: Fusarium guttiforme, Agro-Mos, Bion, fosfitos, silicato.

\section{Abiotic resistance inducers for control of pineapple fusariosis}

\begin{abstract}
The objective of this work was to evaluate the effect of abiotic resistance inducers on the control of pineapple fusariosis (Fusarium guttiforme) in the pre-harvest period, in an area with natural occurrence of the disease in the field, and to check for any physicochemical and biochemical changes in the fruits. The products tested were potassium phosphite, calcium phosphite, copper phosphite, Agro-Mos, calcium silicate, Biopirol, and Bion sprayed on the field, at the dosages recommended by the manufacturers. Potassium phosphite, Biopirol, and copper phosphite were the most effective in reducing the incidence of pineapple fusariosis in the field, with $91.67 \%, 70.01 \%$, and $67.68 \%$ of control, respectively. The physicochemical analyses showed that the treatments did not promote change in $\mathrm{pH}$, total soluble solids, and total acidity of fruits, while, in biochemical analyses, only $\beta$-1,3-glucanase showed lower expression compared with the control (sterilized distilled water), except for the treatment with potassium phosphite. Therefore, foliar fertilization with potassium phosphite and copper phosphite, as well as the treatment with Biopirol, may aid in the control of pineapple fusariosis.
\end{abstract}

Index terms: Fusarium guttiforme, Agro-Mos, Bion, phosphites, silicate.

\section{Introdução}

O abacaxi (Ananas comosus L. Merril) é importante para a economia brasileira (Anuário..., 2013), ocupando o Brasil a $3^{\circ}$ colocação entre os maiores produtores mundiais, com 10,62\% da produção (FAO, 2015). A área plantada em 2014 foi de 96.800 hectares, com 64.673 hectares colhidos, e uma produção de 1.731.879 toneladas, com um rendimento médio de $26.779 \mathrm{~kg} \mathrm{ha}^{-1}$ (Levantamento..., 2015).
A incidência de doenças na cultura pode depreciar a qualidade dos frutos e diminuir a produção (Nogueira et al., 2014). Entre as doenças principais, a fusariose ou gomose é a mais destrutiva, podendo gerar perdas entre 50 e $100 \%$ dos frutos e, também, diminuir em até $50 \%$ a sobrevivência das mudas (Matos, 2003).

$\mathrm{O}$ agente etiológico é o fungo Fusarium guttiforme Nirenberg \& O'Donnell, 1998 (=Fusarium subglutinans f. sp. ananas Ventura, Zambolim \& Gilbertson, 1993) (Nirenberg \& O’Donnell, 1998). A fusariose 
é uma doença que pode ocorrer em qualquer estádio fenológico e órgão da planta, mas o fruto é o local de maior incidência, cujo principal sintoma é a exsudação de uma substância gomosa (Carvalho et al, 2006).

O fitopatógeno é altamente agressivo e seu manejo é realizado com um conjunto de medidas de controle, sendo a redução do inóculo inicial a primeira medida a ser adotada, seguida pelo controle químico (Matos, 2003). No entanto, a utilização de agrotóxicos é a cada dia mais contestada pelos danos causados ao homem e ao ambiente, além de poder promover a resistência de fitopatógenos a fungicidas (Cia et al., 2007). Assim, formas alternativas de controle despertam interesse cada vez maior, levando à investigação e ao desenvolvimento de produtos eficazes e sustentáveis para o controle de fitopatógenos (Deliopoulus et al., 2010).

Uma alternativa promissora é a indução de resistência, a qual ativa mecanismos de defesa latentes da planta (Fernandes et al., 2013) por meio de elicitores contidos em agentes bióticos ou abióticos (Uchôa et al., 2014). Entre os indutores, encontram-se o Biopirol, Acibenzolar-S-Metil (ASM, Bion) (Cruz et al., 2011), fosfitos (Buffara et al., 2013), silicatos (Oliveira et al., 2012) e Agro-Mos (Costa et al., 2010; Gomes et al., 2016).

Os fosfitos, nutrientes constituintes de vários produtos usados no controle de fitopatógenos, podem agir diretamente sobre o patógeno (Spolti et al., 2015) ou indiretamente, induzindo a resistência sistêmica pela síntese de fitoalexinas, compostos fenólicos e PR-proteínas (proteínas relacionadas à patogênese) (Sautter et al., 2008; Carmona \& Sautua, 2011). Nojosa et al. (2009) verificaram inibição de $62,26 \%$ no crescimento micelial in vitro de Phoma costarricensis, pela aplicação de $10 \mathrm{~mL} \mathrm{~L}^{-1}$ de fosfito de potássio.

Os indutores Agro-Mos e Bion também podem atuar no controle de doenças de forma direta ou indireta. O Agro-Mos atua diretamente, formando uma película que impede a fixação de estruturas propagativas dos patógenos, e indiretamente por meio da indução de resistência (Costa et al., 2010). O Bion não possui ação direta sobre o patógeno, mas pode ser rapidamente absorvido pelos tecidos foliares e ativar, sistematicamente, a resistência pela interferência em processos fisiológicos e bioquímicos das plantas (Debona et al., 2009).
Entre os mecanismos de defesa ativados, encontramse genes para expressão de PR-proteínas (Loon et al., 2006), como $\beta$-1,3-glucanases, quitinases e peroxidases, que podem atuar diretamente sobre o patógeno, ou indiretamente, pela indução de resistência na hospedeira (Stangarlin et al., 2011).

O objetivo deste trabalho foi avaliar o efeito de indutores de resistência abióticos no controle da fusariose (Fusarium guttiforme) do abacaxizeiro na fase pré-colheita, em área de ocorrência natural da doença, e verificar se promoveram alterações físico-químicas e bioquímicas nos frutos.

\section{Material e Métodos}

Para verificar a ocorrência do patógeno em campo, foram realizados levantamentos no Município de São Domingos do Maranhão, MA (5³4'33"S; 44²3'6"W), de clima tropical com estação seca, Aw, segundo classificação de Köppen-Geiger. É considerado o maior produtor de abacaxi do Maranhão e, consequentemente, apresenta a maior incidência de fusariose.

O monitoramento da incidência da fusariose foi realizado de acordo com Matos et al. (2009), em função da expressão da sintomatologia. O levantamento foi realizado em quatro áreas de plantio de abacaxi, representando um total de 70 hectares, e de 3.000 plantas amostradas.

O experimento foi instalado em plantio comercial, onde foi constatada elevada incidência da doença, na Fazenda Conduru, Município de São Domingos do Maranhão, em 2014/2015. Os tratamentos foram: fosfito de potássio (FK) $1 \mathrm{~g} \mathrm{~L}^{-1}$, fosfito de cálcio (FCa) $1 \mathrm{~g} \mathrm{~L}^{-1}$, fosfito de cobre (FCu) $1 \mathrm{~g} \mathrm{~L}^{-1}$, Agro-Mos (AGM) $1 \mathrm{~mL} \mathrm{~L}^{-1}$, silicato de cálcio $(\mathrm{SCa}) 1 \mathrm{~g} \mathrm{~L}^{-1}$, Biopirol $1 \mathrm{~mL} \mathrm{~L}^{-1}$, Bion 0,01g L $\mathrm{g}^{-1}$, Testemunha (água destilada esterilizada) e o Carbendazim CCAB 500 $\mathrm{SC} 1 \mathrm{~mL} \mathrm{~L}^{-1}$, que foi utilizado apenas como referência de controle químico convencional utilizado pelos produtores de abacaxi. As doses foram estabelecidas conforme especificações dos fabricantes (Tabela 1).

Utilizou-se o delineamento de blocos ao acaso. As 36 parcelas foram constituídas de 13 plantas em fileiras duplas, alternadas por duas fileiras de bordadura, totalizando 1.872 plantas. Cada planta recebeu os tratamentos por pulverizações distribuídas em quatro aplicações (uma na fase vegetativa e três na fase reprodutiva), em intervalos de 30 dias. Foi 
utilizado um pulverizador costal com bico cone, e o volume utilizado foi calculado sobre $500 \mathrm{~L}$ de calda por hectare.

A avaliação ocorreu 20 dias após a última pulverização, pela quantificação da incidência da fusariose nos frutos, sendo as médias comparadas pelo teste de Tukey a 5\% de probabilidade. Os frutos foram colhidos, pesados e, após esta primeira triagem, levados ao Laboratório de Fitopatologia da Universidade Estadual do Maranhão para as análises bioquímicas e físico-químicas.

A ausência da inoculação artificial das plantas foi justificada pelo fato de que para ter uma produção constante, os produtores fazem plantio escalonado, que favorece a permanência contínua do patógeno no campo.

Após a colheita, os frutos submetidos aos tratamentos foram avaliados em relação às características físico-químicas: teor de sólidos solúveis totais (SST), acidez total titulável (ATT) e potencial hidrogeniônico $(\mathrm{pH})$. Para análise de ATT, foi utilizada a técnica descrita na Association of Official Analytical Chemists (AOAC) (Helrich, 1990). Foi extraída a polpa de cada abacaxi, e pesados $3 \mathrm{~g}$ diluídos em $50 \mathrm{~mL}$ de água destilada. Para a titulação, foram utilizados $10 \mathrm{~mL}$ do suco. Os resultados foram registrados em porcentagem de ácido cítrico. A aferição do $\mathrm{pH}$ foi realizada em potenciômetro (Quimis Q400A), devidamente calibrado, e o teor de sólidos solúveis totais foi obtido por meio da leitura em um refratômetro (Atago master $\mathrm{T}$ ), graduado de zero a $32^{\circ}$ Brix.

Tabela 1. Indutores de resistência abióticos aplicados em plantio comercial de abacaxi com fusariose, no Município de São Domingos do Maranhão, MA.

\begin{tabular}{lccc}
\hline Produto comercial & Fabricante & Composição & $\begin{array}{c}\text { Concentração } \\
\text { recomendada }\end{array}$ \\
\hline Fosfitotal $^{\circledR}$ - Cálcio & Intercuf & $\begin{array}{c}\text { Fósforo }\left(\mathrm{P}_{2} \mathrm{O}_{5}\right) \mathrm{e} \\
\text { Cálcio }(\mathrm{Ca})\end{array}$ & $1 \mathrm{~g} \mathrm{~L}^{-1}$ \\
Fosfitotal $^{\circledR}$ - Potássio & Intercuf & $\begin{array}{c}\text { Fósforo }\left(\mathrm{P}_{2} \mathrm{O}_{5}\right) \mathrm{e} \\
\text { Potássio }(\mathrm{K})\end{array}$ & $1 \mathrm{~g} \mathrm{~L}^{-1}$ \\
Fosfitotal $^{\circledR}$ - Cobre & Intercuf & $\begin{array}{c}\text { Fósforo }\left(\mathrm{P}_{2} \mathrm{O}_{5}\right) \\
\text { e Cobre }(\mathrm{Cu})\end{array}$ & $1 \mathrm{~g} \mathrm{~L}^{-1}$ \\
Silicato de cálcio & $\begin{array}{c}\text { Sigma- } \\
\text { Aldrich }\end{array}$ & $\left.\begin{array}{c}\text { Óxido de cálcio }(\mathrm{CaO}) \mathrm{e} \\
\text { óxido de silício }(\mathrm{SiO}\end{array}\right)$ & $1 \mathrm{~g} \mathrm{~L}^{-1}$ \\
Agro-Mos $^{\circledR}$ & $\begin{array}{l}\text { Improcrop } \\
\text { Sulfato de cobre, sulfato } \\
\text { de zinco e complexado por } \\
\text { aminoácidos }\end{array}$ & $1 \mathrm{~mL} \mathrm{~L}^{-1}$ \\
Biopirol $^{\circledR}$ & $\begin{array}{c}\text { Extrato pirolenhoso } \\
\text { Bion }^{\circledR}\end{array}$ & $\begin{array}{c}\text { Biocarbo } \\
\text { Syngenta }\end{array}$ & $\begin{array}{c}\text { Acibenzolar-S-Metil } \\
0.01 \mathrm{~g} \mathrm{~L}^{-1}\end{array}$ \\
\hline
\end{tabular}

O preparo do extrato enzimático bruto para avaliação das atividades enzimáticas foi realizado um dia após a colheita dos frutos. Para retirada da amostra, foi utilizado o terço médio de cada um dos frutos (sadios e doentes) que compunham as parcelas tratadas. As amostras de $1,0 \mathrm{~g}$ de polpa de cada fruto tratado foram maceradas em almofariz com nitrogênio líquido e adição de $1 \%(\mathrm{v} / \mathrm{v})$ de polivinilpirrolidona (PVP), $5 \mathrm{~mL}$ de tampão acetato de sódio (0,1 M, pH 5) e $1 \mathrm{~mL}$ de EDTA (1 mM). Os extratos foram centrifugados a $10.000 \mathrm{~g}$ por 10 minutos a $4^{\circ} \mathrm{C}$, e o sobrenadante foi transferido para tubos tipo eppendorf de $2 \mathrm{~mL}$, armazenados a $-80^{\circ} \mathrm{C}$. $\mathrm{O}$ extrato enzimático produzido foi utilizado para as determinações de proteínas solúveis totais (Bradford, 1976) e das atividades de peroxidase, polifenoloxidase e $\beta$-1,3-glucanase.

A atividade de polifenoloxidase (E. C. 1.10.3.1) foi quantificada segundo Hyodo \& Yang (1971). A atividade enzimática específica foi definida como a variação de absorbância a $410 \mathrm{~nm}$ produzida em meio reacional, por tempo em minutos e por miligrama de

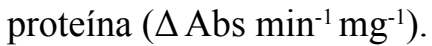

A atividade da peroxidase (E.C. 1.11.1.7) foi definida como a variação de absorbância a $470 \mathrm{~nm}$ produzida em meio reacional, por tempo em minutos e por miligrama de proteína $\left(\Delta \mathrm{Abs} \mathrm{min}^{-1} \mathrm{mg}^{-1}\right)($ Dann \& Deverall, 2000).

A determinação de $\beta$-1,3-glucanase (E.C. 3.2.1.29) foi realizada pela dosagem da glicose liberada pela hidrólise da laminarina (Somogyi, 1952). A curva padrão de glicose foi preparada com a adição de padrão, da mesma forma que as amostras, tendo-se substituído a laminarina por soluções de glicose $\left(0-300 \mathrm{mg} \mathrm{L}^{-1}\right)$.

\section{Resultados e Discussão}

Nas áreas de abacaxizeiros em estádio reprodutivo, a incidência da doença chegou a 82,6\%, incluindo sintomas tanto nos frutos quanto nos filhotes, com gomose aparente. Esse elevado patamar de ocorrência da fusariose em São Domingos do Maranhão e na maioria dos demais municípios produtores reforça a necessidade de introdução de cultivares resistentes ou de utilização de produto alternativo ao controle químico, que induza a resistência da planta e/ou controle a ação do fitopatógeno.

Pesq. agropec. bras., Brasília, v.51, n.10, p.1703-1709, out. 2016 DOI: 10.1590/S0100-204X2016001000001 
Entre os indutores de resistência testados, somente FCa não resultou em diminuição da incidência da fusariose nos frutos (Figura 1). O FK levou ao índice de incidência de apenas 8,33\% dos frutos sintomáticos, mas não diferiu estatisticamente do Biopirol e do $\mathrm{FCu}$, tendo-se assemelhado ao controle químico convencional com Carbendazim. Fosfito de potássio também foi eficaz no tratamento da antracnose da goiabeira, ao reduzir o diâmetro das lesões e manter a qualidade pós-colheita dos frutos (Gomes et al., 2016).

Diferentemente dos outros tratamentos, o FCa não apresentou bom nível de controle, e não diferiu da testemunha. Resultado similar foi obtido por Moreira \& May-De Mio (2006), que verificaram que o FK se mostrou mais eficiente que o FCa no controle da podridão-parda do pessegueiro.

Os resultados demonstraram que a incidência da doença foi proporcional à diminuição do peso dos frutos. O tratamento com $\mathrm{FCa}$ apresentou a maior incidência da fusariose, com $91,66 \%$ de frutos

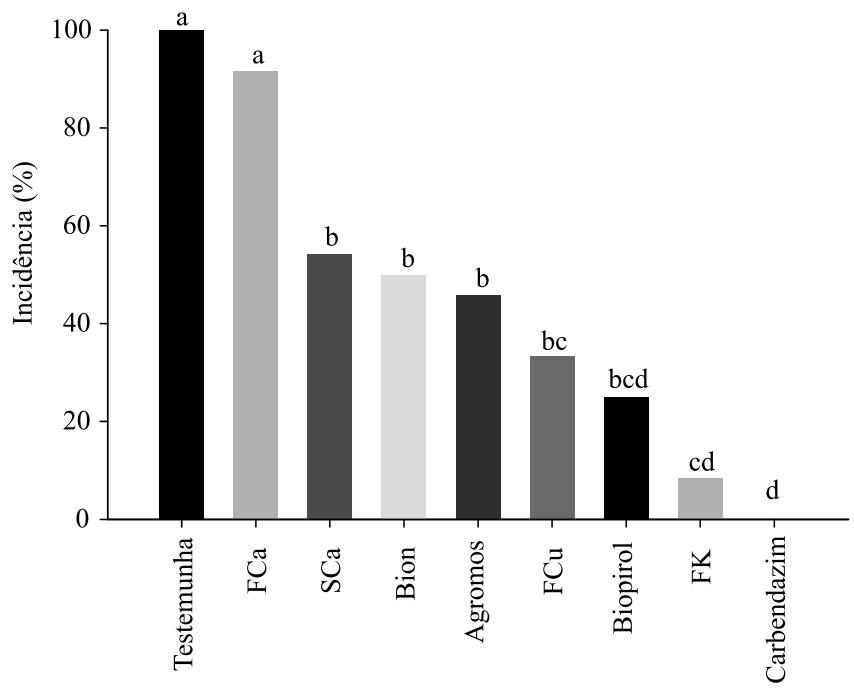

Figura 1. Incidência de fusariose em abacaxizeiro, em função da aplicação de indutores de resistência abióticos em pré-colheita, em São Domingos do Maranhão, MA. Testemunha, água destilada esterilizada; $\mathrm{FCa}$, fosfito de cálcio $1 \mathrm{~g} \mathrm{~L}^{-1}$; $\mathrm{SCa}$, silicato de cálcio $1 \mathrm{~g} \mathrm{~L}^{-1}$; Bion, $0,01 \mathrm{~g} \mathrm{~L}^{-1}$; Agro-Mos, $1 \mathrm{~mL} \mathrm{~L}^{-1}$; $\mathrm{FCu}$, fosfito de cobre $1 \mathrm{~g} \mathrm{~L}^{-1}$; Biopirol, $1 \mathrm{~mL} \mathrm{~L}^{-1}$; FK, fosfito de potássio $1 \mathrm{~g} \mathrm{~L}^{-1}$; Carbendazim, $1 \mathrm{~mL}$ $\mathrm{L}^{-1}$. Colunas com letras iguais não diferem entre si pelo teste de Tukey a $5 \%$ de probabilidade. CV (coeficiente de variação) $=21,17 \%$. afetados, e levou ao menor ganho de peso, com frutos apresentando em média 0,549 kg (Figura 2).

As análises físico-químicas dos frutos tratados com bioindutores mostraram que não houve diferença significativa para SST, pH e ATT, com exceção do Bion e do silicato de cálcio, que apresentaram valores de ${ }^{\circ}$ Brix menores que os demais tratamentos (Tabela 2).

A acidez total titulável representa uma das melhores formas de avaliação do grau de doçura da fruta, sendo, portanto, uma variável a ser considerada na caracterização do sabor (Chitarra \& Chitarra, 2005).

Estes resultados eram esperados, visto que as mudanças metabólicas mais importantes que podem refletir na qualidade final dos frutos relacionam-se com a última etapa do amadurecimento (Carvalho \& Botrel, 1996), em que aumentam os teores de açúcares redutores e sacarose, refletindo diretamente no aumento relevante dos sólidos solúveis ( ${ }^{\circ}$ Brix) e dos compostos voláteis, intensificando o aroma, e também conferindo sabor mais adocicado aos frutos.

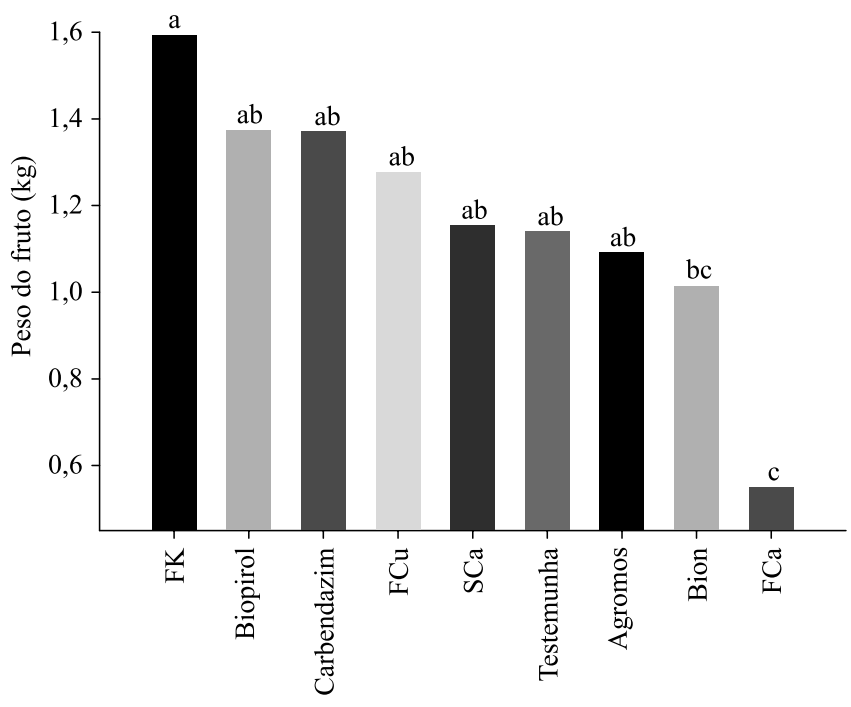

Figura 2. Peso de frutos de abacaxi em função da aplicação de indutores de resistência abióticos em pré-colheita, em São Domingos do Maranhão, MA. FK, fosfito de potássio $1 \mathrm{~g} \mathrm{~L}^{-1}$; Biopirol, $1 \mathrm{~mL} \mathrm{~L}^{-1}$; Carbendazim, $1 \mathrm{~mL} \mathrm{~L}^{-1} ; \mathrm{FCu}$, fosfito de cobre $1 \mathrm{~g} \mathrm{~L}^{-1}$; $\mathrm{SCa}$, silicato de cálcio $1 \mathrm{~g} \mathrm{~L}^{-1}$; testemunha, água destilada esterilizada; Agro-Mos, $1 \mathrm{~mL} \mathrm{~L}^{-1}$; Bion, 0,01 $\mathrm{g} \mathrm{L}^{-1}$; FCa, fosfito de cálcio $1 \mathrm{~g} \mathrm{~L}^{-1}$. Colunas com letras iguais não diferem entre si pelo teste de Tukey a $5 \%$ de probabilidade. CV $($ coeficiente de variação $)=18,21 \%$. 
Tabela 2. Características físico-químicas de frutos de abacaxi pulverizados em pré-colheita com indutores de resistência abióticos, em São Domingos do Maranhão, $\mathrm{MA}^{(1)}$.

\begin{tabular}{lcccc}
\hline Tratamento & Concentração & $\mathrm{pH}$ & $\mathrm{SST}\left({ }^{\circ}\right.$ Brix $)$ & ATT \\
\hline Testemunha & - & $3,99 \mathrm{ab}$ & $13,21 \mathrm{ab}$ & $0,77 \mathrm{~b}$ \\
Fosfito de potássio & $1 \mathrm{~g} \mathrm{~L}^{-1}$ & $3,99 \mathrm{ab}$ & $13,95 \mathrm{a}$ & $0,81 \mathrm{ab}$ \\
Fosfito de cálcio & $1 \mathrm{~g} \mathrm{~L}^{-1}$ & $4,09 \mathrm{a}$ & $14,12 \mathrm{a}$ & $0,92 \mathrm{a}$ \\
Fosfito de cobre & $1 \mathrm{~g} \mathrm{~L}^{-1}$ & $4,00 \mathrm{ab}$ & $13,87 \mathrm{a}$ & $0,83 \mathrm{ab}$ \\
Silicato de cálcio & $1 \mathrm{~g} \mathrm{~L}^{-1}$ & $3,96 \mathrm{ab}$ & $11,67 \mathrm{bc}$ & $0,83 \mathrm{ab}$ \\
Agro-Mos & $1 \mathrm{~mL} \mathrm{~L}^{-1}$ & $4,10 \mathrm{a}$ & $13,35 \mathrm{a}$ & $0,85 \mathrm{ab}$ \\
Bion & $0,01 \mathrm{~g} \mathrm{~L}^{-1}$ & $3,87 \mathrm{~b}$ & $11,33 \mathrm{c}$ & $0,82 \mathrm{ab}$ \\
Biopirol & $1 \mathrm{~mL} \mathrm{~L}^{-1}$ & $3,96 \mathrm{ab}$ & $13,33 \mathrm{ab}$ & $0,92 \mathrm{ab}$ \\
Carbendazim & $1 \mathrm{~mL} \mathrm{~L}^{-1}$ & $4,08 \mathrm{a}$ & $13,67 \mathrm{a}$ & $0,94 \mathrm{a}$ \\
\hline CV (\%) & & 4,15 & 12,70 & 17,51 \\
\hline
\end{tabular}

${ }^{(1)}$ Médias seguidas por letras iguais, nas colunas, não diferem entre si pelo teste de Tukey a $5 \%$ de probabilidade. Testemunha, água destilada esterilizada; $\mathrm{pH}$, potencial hidrogeniônico; SST, sólidos solúveis totais; ATT, acidez total titulável; e CV, coeficiente de variação.
Não foram verificadas diferenças significativas para a atividade enzimática de peroxidase e polifenoloxidase, nos frutos submetidos ao tratamento com os indutores de resistência. A atividade da PR-proteína $\beta$-1,3-glucanase não diferiu da testemunha apenas no tratamento com FK, enquanto os demais indutores de resistência levaram à diminuição da expressão dessa enzima (Figura 3).

As atividades baixas de peroxidase e polifenoloxidase podem estar relacionadas ao tempo decorrido entre a aplicação dos indutores e a colheita dos frutos. Peroxidases estão relacionadas às primeiras respostas de defesa da hospedeira à infecção por patógenos (Tuzun, 2001) e estão integradas a vários processos fisiológicos na planta, tais como a lignificação, o catabolismo de auxinas, suberização, formação e

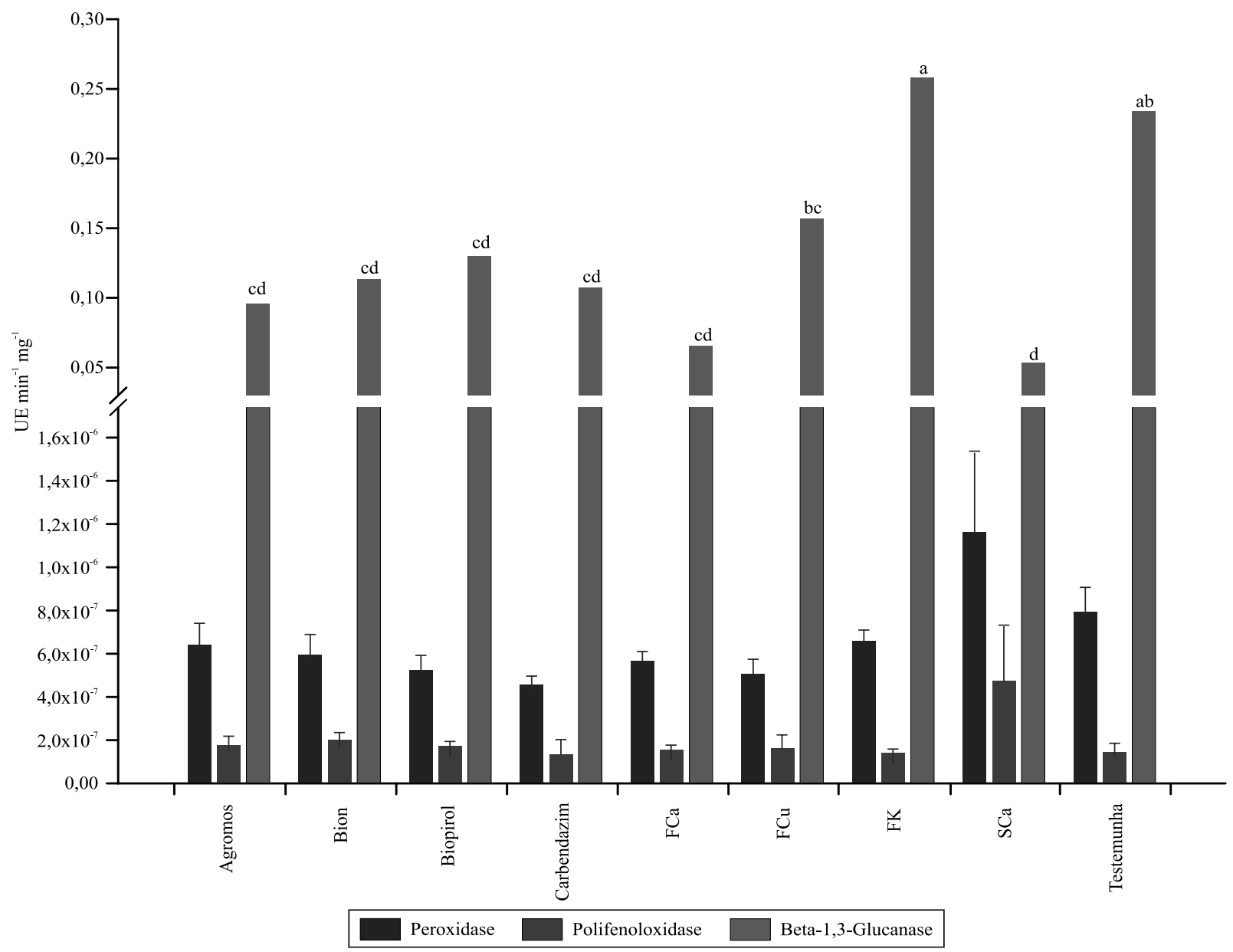

Figura 3. Atividades das enzimas peroxidase, polifenoloxidase e $\beta$-1,3-glucanase em frutos de abacaxizeiro pulverizados em pré-colheita com indutores de resistência abióticos. Agro-Mos, $1 \mathrm{~mL} \mathrm{~L}^{-1}$; Bion, $0,01 \mathrm{~g} \mathrm{~L}^{-1}$; Biopirol, $1 \mathrm{~mL} \mathrm{~L}^{-1}$; Carbendazim, $1 \mathrm{~mL} \mathrm{~L}^{-1} ; \mathrm{FCa}$, fosfito de cálcio $1 \mathrm{~g} \mathrm{~L}^{-1} ; \mathrm{FCu}$, fosfito de cobre $1 \mathrm{~g} \mathrm{~L}^{-1} ; \mathrm{FK}$, fosfito de potássio $1 \mathrm{~g} \mathrm{~L}^{-1}$; $\mathrm{SCa}$, silicato de cálcio $1 \mathrm{~g} \mathrm{~L}^{-1}$; testemunha, água destilada esterilizada. Colunas com letras iguais não diferem entre si pelo teste de Tukey a $5 \%$ de probabilidade. 
reticulação de componentes da parede celular e senescência (Nascimento \& Barrigossi, 2014). Sua atividade na planta diminui em relação ao tempo decorrido após a exposição inicial a um agente indutor (Macagnan et al., 2008).

\section{Conclusões}

1. Fosfito de potássio e Biopirol, pulverizados em pré-colheita de abacaxi, são os mais eficientes indutores de resistência abióticos para a redução da incidência da fusariose nos frutos, equiparando-se ao controle com Carbendazim.

2. Abacaxizeiros tratados com Bion e fosfito de cálcio apresentam os menores frutos.

3. Os valores de sólidos solúveis totais, acidez total titulável, $\mathrm{pH}$ e das atividades de peroxidase e polifenoloxidase não são alterados em frutos de abacaxi tratados pelos indutores de resistência abióticos, com exceção do Bion e do silicato de cálcio, que reduzem o teor de sólidos solúveis totais.

4. A atividade de $\beta$-1,3-glucanase diminui com a aplicação dos indutores de resistência abióticos nos frutos, e apenas o fosfito de potássio não influencia essa enzima.

\section{Agradecimentos}

Ao Conselho Nacional de Desenvolvimento Científico e Tecnológico (CNPq), pelo apoio financeiro; e à Fazenda Conduru, pela cessão da área experimental.

\section{Referências}

ANUÁRIO BRASILEIRO DA FRUTICULTURA 2014. Santa Cruz do Sul: Editora Gazeta Santa Cruz, 2013. 136p.

BRADFORD, M.M. A rapid and sensitive method for the quantification of microgram quantities of protein utilizing the principle of protein-dye binding. Analytical Biochemistry. v.72, p.248-254, 1976. DOI: 10.1016/0003-2697(76)90527-3.

BUFFARA, C.R.S.; ANGELOTTI, F.; TESSMANN, D.J.; SOUZA, C.D. de; VIDA, J.B. Atividade de fosfito de potássio na pré e pós-infecção de Phakopsora euvitis em folhas de videira. Semina: Ciências Agrárias, v.34, p.3333-3340, 2013. DOI: 10.5433/1679-0359.2013v34n6Supl1p3333.

CARMONA, M.; SAUTUA, F. Os fosfitos no manejo de doenças nas culturas extensivas. Revista Plantio Direto, v.126, p.19-22, 2011.
CARVALHO, R.A.; LACERDA, J.T. de; OLIVEIRA, E.F. de; CHOAIRY, S.A.; BARREIRO NETO, M.; SANTOS, E.S. dos. Controle agroecológico da fusariose do abacaxi com plantas antibióticas. 2006. Disponível em: $<\mathrm{http}$ ://www.infobibos.com/ Artigos/2006_2/abacaxi/Index.htm>. Acesso em: 12 jan. 2016.

CARVALHO, V.D. de; BOTREL, N. Características da fruta para exportação. In: GORGATTI NETTO, A.; CARVALHO, V.D. de; BOTREL, N.; BLEINROTH, E.W.; MATALLO, M.; GARCIA, A.E.; ARDITO, E.F.G.; GARCIA, E.E.C.; BORDIN, M.R. Abacaxi para exportação: procedimentos de colheita e pós-colheita. Brasília: EMBRAPA-SPI, 1996. 41p. (Frupex. Publicações técnicas, 23).

CHITARRA, M.I.F.; CHITARRA, A.B. Pós-colheita de frutos e hortaliças: fisiologia e manuseio. 2.ed. rev. e ampl. Lavras: Ed. da Ufla, 2005. 785p.

CIA, P.; PASCHOLATI, S.F.; BENATO, E.A. Indução de resistência no manejo de doenças pós-colheita. In: RODRIGUES, F.A.; ROMEIRO, R.S. Indução de resistência em plantas a patógenos. Viçosa: Ed. da UFV, 2007. p.245-280.

COSTA, J. de C.B.; RESENDE, M.L.V. de; RIBEIRO JÚNIOR, P.M.; CAMILO, F.R.; MONTEIRO, A.C.A.; PEREIRA, R.B. Indução de resistência em mudas de cacaueiro contra Moniliophthora perniciosa por produto à base de mananoligossacarídeo fosforilado. Tropical Plant Pathology, v.35, p.285-294, 2010.

CRUZ, S.M. da C.; RODRIGUES, A.A.C.; COELHO, R.S.B.; SARDINHA, D.H.S. Ação indutora de produtos abióticos na resistência de tomateiro e efeito sobre o crescimento micelial de Fusarium oxysporum f. sp. Lycopersici. Idesia, v.29, p.111-118, 2011. DOI: $10.4067 / \mathrm{S} 0718-34292011000200015$.

DANN, E.K.; DEVERALL, B.J. Activation of systemic disease resistance in pea by an avirulent bacterium or benzothiadiazole, but not by a fungal leaf spot pathogen. Plant Pathology, v.49, p.324-332, 2000. DOI: 10.1046/j.1365-3059.2000.00457.x.

DEBONA, D.; FIGUEIRÓ, G.G.; CORTE, G.D.; NAVARINI, L.; DOMINGUES, L. da S.; BALARDIN, R.S. Efeito do tratamento de sementes com fungicidas e acibenzolar-S-methyl no controle da ferrugem asiática e crescimento de plântulas em cultivares de soja. Summa Phytopathologica, v.35, p.26-31, 2009. DOI: 10.1590/ S0100-54052009000100004.

DELIOPOULUS, T.; KETTLEWELL, P.S.; HARE, M.C. Fungal disease suppression by inorganic salts: a review. Crop Protection, v.29, p.1059-1075, 2010. DOI: 10.1016/j.cropro.2010.05.011.

FAO. FOOD AND AGRICULTURE ORGANIZATION OF THE UNITED NATIONS. FAOSTAT. [Rome]: FAO, 2015. Disponível em: <http://faostat. fao.org/site/567/default.aspx\#ancor>. Acesso em: 2 dez. 2015.

FERNANDES, L.H.M.; RESENDE, M.L.V. de; PEREIRA, R.B.; COSTA, B.H.G.; MONTEIRO, A.C.A.; RIBEIRO JÚNIOR, P.M. Acibenzolar-s-metil no controle da ferrugem e da cercosporiose do cafeeiro em condições de campo. Coffee Science, v.8, p.24-32, 2013.

GOMES, R. dos S.S.; DEMARTELAERE, A.C.F.; NASCIMENTO, L.C. do; MACIEL, W.O.; WANDERLEY, D.B.N. da S. Bioatividade de indutores de resistência no manejo da antracnose da goiabeira (Psidium guajava L.). 
Summa Phytopathologica, v.42, p.149-154, 2016. DOI: 10.1590/0100-5405/2103.

HELRICH, K.. Official methods of analysis of the AOAC. $15^{\text {th }}$. Arlington: Association of Official Analytical Chemists, 1990. p.685-1213.

HYODO, H.; YANG, S.F. Ethylene-enhanced synthesis of phenylalanine ammonia lyase in pea seedlings. Plant Physiology, v.47, p.765-770, 1971.

LEVANTAMENTO SISTEMÁTICO DA PRODUÇÃO AGRÍCOLA. Rio de Janeiro: IBGE, v.29, n.1, 2015. 83p. Disponível em: $\quad<\mathrm{ftp}: / / \mathrm{ftp}$. ibge.gov.br/Producao_Agricola/Levantamento Sistematico_da_Producao_Agricola_\%5Bmensal\%5D/Fasciculo/ 1spa_201501.pdf $>$. Acesso em: 10 out. 2015.

LOON, L.C. van; REP, M.; PIETERSE, C.M.J. Significance of inducible defense-related proteins in infected plants. Annual Review of Phytopathology, v.44, p.135-162, 2006. DOI: 10.1146/ annurev.phyto.44.070505.143425.

MACAGNAN, D.; ROMEIRO, R. da S.; BARACAT-PEREIRA, M.C.; LANNA-FILHO, R.; BATISTA, G.S.; POMELLA, A.W.V. Atividade de enzimas associadas ao estado de indução em mudas de cacaueiro expostas a dois actinomicetos residentes de filoplano. Summa Phytopathologica, v.34, p.34-37, 2008. DOI: 10.1590/ S0100-54052008000100007.

MATOS, A.P. de; SANCHES, N.F.; TEXEIRA, F.A.; SIMÃO, A.H.; GOMES, D.C.; ELIAS JUNIOR, J. Monitoramento da fusariose em plantios de abacaxi 'Pérola' conduzidos em sistema de produção integrada no Estado do Tocantins. Cruz das Almas: Embrapa Mandioca e Fruticultura Tropical, 2009. 36p. (Embrapa Mandioca e Fruticultura Tropical. Documentos, 184).

MATOS, A.P. Doenças do abacaxizeiro. In: FREIRE, F. das C.O.; CARDOSO, J.E.; VIANA, F.M.P. (Ed.). Doenças de fruteiras tropicais de interesse agroindustrial. Brasília: Embrapa Informação Tecnológica; Fortaleza: Embrapa Agroindústria Tropical, 2003. p.16-55.

MOREIRA L.M.; MAY-DE MIO, L.L. Efeito de fungos antagonistas e produtos químicos no controle da podridão parda em pomares de pessegueiro. Floresta, v.36, p.287-293, 2006. DOI: 10.5380/rf.v36i2.6448.

NASCIMENTO, J.B.; BARRIGOSSI, J.A.F. O papel das enzimas antioxidantes na defesa das plantas contra insetos herbívoros e fitopatógenos. Agrarian Academy, v.1, p. 234-250, 2014. DOI: 10.18677/Agrarian_Academy_2014_021.
NIRENBERG, H.I.; O'DONNELL, K. New Fusarium species and combinations within the Gibberella fujikuroi species complex. Mycologia, v.90, p.434-458, 1998. DOI: 10.2307/3761403.

NOGUEIRA, S.R.; LIMA, F.S.O.; ROCHA, E.M.; ARAÚJO, D.H.M. Fungicidas no controle de fusariose do abacaxi no estado de Tocantins, Brasil. Revista de Ciências Agrárias, v.37, p.447-455, 2014.

NOJOSA, G.B.A.; RESENDE, M.L.V.; BARGUIL, B.M.; MORAES, S.R.G.; VILAS BOAS, C.H. Efeito de indutores de resistência em cafeeiro contra a mancha de Phoma. Summa Phytopathologica, v.35, p.60-62, 2009. DOI: 10.1590/ S0100-54052009000100011.

OLIVEIRA, R.M.; RIBEIRO, R.C.F.; XAVIER, A.A.; PIMENTA, L.; KORNDORFER, G.H. Efeito do silicato de cálcio e magnésio sobre a reprodução de Meloidogyne javanica e desenvolvimento de mudas de bananeira prata-anã. Revista Brasileira de Fruticultura, v.34, p.409-415, 2012. DOI: 10.1590/ S0100-29452012000200013.

SAUTTER, C.K.; STORCK, L.; RIZZATI, M.R.; MALLMANN, C.A.; BRACKMANN, A. Síntese de trans-resveratrol e controle de podridão em maçãs com uso de elicitores em pós-colheita. Pesquisa Agropecuária Brasileira, v.43, p.1097-1103, 2008. DOI: 10.1590/S0100-204X2008000900001.

SOMOGYI, M. Notes on sugar determination. Journal of Biological Chemistry, v.195, p.19-23, 1952.

SPOLTI, P.; VALDEBENITO-SANHUEZA, R.M.; CAMPOS, A.D.; DEL PONTE, E.M. Modo de ação de fosfitos de potássio no controle da podridão olho de boi em maçã. Summa Phytopathologica, v.41, p.42-48, 2015. DOI: 10.1590/0100-5405/1982.

STANGARLIN, J.R.; KUHN, O.J.; TOLEDO, M.V.; PORTZ, R.L.; SCHWAN-ESTRADA, K.R.F.; PASCHOLATI, S.F. A defesa vegetal contra fitopatógenos. Scientia Agraria Paranaenis, v.10, p.18-46, 2011.

TUZUN, S. The relationship between pathogen-induced systemic resistance (ISR) and multigenic (horizontal) resistance in plants. Europeam Journal of Plant Pathology, v.107, p.85-93, 2001. DOI: $10.1023 / \mathrm{A}: 1008784417222$.

UCHÔA, C. do N.; POZZA, E.A.; UCHÔA, K.S.A.; RIBEIRO JÚNIOR, P.M.; TOYOTA, M.; MORAES, W. da S.; FREITAS, M.L. de O.; SILVA, B.M. da. Acibenzolar-S-Metil e silício como indutores de resistência à Sigatoka-negra em bananeira cultivar Grand Naine (AAA). Revista Agrarian, v.7, p.189-196, 2014.

Recebido em 28 de abril de 2016 e aprovado em 26 de agosto de 2016

Pesq. agropec. bras., Brasília, v.51, n.10, p.1703-1709, out. 2016 DOI: 10.1590/S0100-204X2016001000001 